\title{
Respecting Autonomy in Population Policy: An Argument for International Family Planning Programs
}

\author{
Benjamin S. Hale, Philosophy and Environmental Studies, University of Colorado, \\ Boulder
Lauren Hale*, Department of Preventive Medicine, State University of New York, Stony Brook

*Corresponding author: Lauren Hale, Department of Preventive Medicine, State University of New York, Stony Brook, Stony Brook, NY, USA. Email: Ihale@notes.cc.sunysb.edu

This paper addresses whether universal, general education programs are enough to satisfy basic criteria of human rights or whether comprehensive family planning programs, in conjunction with universal education programs, might also be morally required. Even before the Reagan administration instituted the 'global gag rule' at the 1984 conference in Mexico City, prohibiting funding to nongovernmental organizations that included providing information about abortion as a possible method of family planning, the moral acceptability of family planning programs has been called into question. This paper makes a moral argument for family planning by appealing to both data and theory: data about the efficacy of universal and comprehensive family planning education programs at reducing fertility and infant mortality and theory about what is required for the establishment of autonomy. It reasons that universal educational programs are insufficient for the promotion of autonomy and, therefore, argues on substantive autonomy grounds for comprehensive family planning programs in addition to universal education programs.

\section{Introduction}

For several decades, the international population community has debated the relative merits of 'comprehensive' family planning and education programs versus 'universal' education programs as a means to improve women's autonomy and reduce unwanted fertility and infant and child mortality. Both comprehensive family planning and universal education programs have been demonstrated to reduce fertility and infant mortality. Generally speaking, however, comprehensive family planning education programs are frequently framed either as morally inappropriate or as a tradeoff with other possible government projects.

Apart from efficacy and resource questions, there are also deeper questions regarding rights and autonomy that have been overshadowed by the view that comprehensive family planning programs cross a moral boundary (by introducing information about fertility and women's health concerns) where universal education programs do not. In this paper, we address the normative question of whether a simple universal education program is enough to satisfy basic criteria of human rights or whether a comprehensive family planning education program, in conjunction with a universal education program, may also be required. In the next section, we outline the historical and international backdrop upon which this discussion about universal education programs and family planning programs rests. Then we offer empirical support of how family planning programs offer autonomy. Next we argue on fairness grounds for family planning programs in addition to universal education, before we conclude.

\section{Background}

The International Conference on Human Rights in Tehran in 1968 was the first international forum to declare that 'parents have a basic human right to determine freely and responsibly the number and spacing 
of their children.' This sentiment has been reaffirmed in all subsequent United Nations Conferences on Population, although the policy implication has varied.

For instance, at the 1974 World Population Conference in Bucharest, policy discussions focused on economic development, resulting in the 'development is the best contraceptive' model of slowing population growth. This policy was met with a significant objection. Many countries in the developed world argued that overpopulation is the cause of, rather than a consequence of, underdevelopment (Finkle and Crane, 1975; Bernstein, 2005).

In contrast to the 1974 Bucharest conference, which highlighted the development goals to reduce population, the 1984 United Nations International Conference on Population in Mexico City emphasized demographic targets and urged for family planning as a mechanism for reducing rapid population growth (Finkle and Crane, 1985; Bernstein, 2005). This too was met with a significant objection. Some countries, the USA in particular, refused as a matter of policy to accept some of the implications of family planning programs. It was at this conference that the Reagan Administration, for instance, announced that the USA would not provide aid money to any organization that promoted or performed abortions as a method of family planning.

The tide-turning 1994 International Conference on Population and Development in Cairo shifted the international dialogue towards emphasizing gender equality by providing women with greater opportunity: through expanded access to education, health services, skill development, employment and political participation (Mcintosh and Finkle, 1995). The resulting 'Programme for Action' from this conference included recommendations to use both universal education and family planning services.

Unfortunately, resource questions regarding the extent to which these comprehensive family planning educational programs are possible still linger, and they are therefore seen by some as desirable but not necessary. In addition, some global leaders around the world are opposed to comprehensive family planning programs and are often influenced by the Catholic Church. For example, in 2005, Philippine President Arroyo told the U.N. General Assembly that natural family planning is more effective than condoms and other forms of modern contraception (Son, 2005). The Catholic Church maintains that sex is meant for procreation, and thus, the use of condoms promotes adultery and is immoral, even in the case of prevention against HIV/AIDS and other sexually transmitted diseases.

\section{Universal Education}

Proponents of universal education believe 'that all children, young people and adults have the human right to benefit from an education that will meet their basic learning needs in the best and fullest sense of the term, an education that includes learning to know, to do, to live together and to be. It is an education geared to tapping each individual's talents and potential, and developing learners' personalities, so that they can improve their lives and transform their societies.' This perspective was declared first in the World Declaration on Education for All and supported by the Universal Declaration of Human Rights and the Convention on the Rights of the Child. ${ }^{1}$

The aims of such programs designed to provide universal education (e.g., the 2000 Dakar Program of Action) generally include the following: (i) expanding and improving childhood care and education programs, particularly for disadvantaged population, (ii) providing access to a completely free and compulsory highquality primary education, (iii) meeting the learning needs of young people and adults through educational programs, (iv) providing equitable access to basic and continuing education for adults, (v) eliminating gender disparities in primary and secondary education and (vi) achieving measurable learning objectives particularly with regard to literacy, numeracy and essential life skills.

The term 'universal education' thus refers to at least two dimensions of universality: that the education be made available to all, universally, and that the education provides a universally applicable curriculum, geared to foster and tap 'each individual's talents and potential'. Both variants are of interest to us, though the latter dimension bears strongly on the question of whether to provide comprehensive family planning education. For this reason, we will refer to this aspect of universal education as 'general education' and seek to distinguish the two where necessary. Moreover, for the purpose of this paper, we suppose that the so-called 'right' to universal education stems from autonomy and thus can be supported by a roughly Kantian or Rawlsian view (Rawls, 1993; Levinson, 1999; Weber, 2008).

\section{Comprehensive Family Planning Education}

In addition to universal education, many in the international population community argue for programs that develop particular comprehensive family planning skills, often called Maternal and Child Health and Family Planning (MCH/FP) programs. 
$\mathrm{MCH} / \mathrm{FP}$ programs typically provide services that help couples space their pregnancies, prevent unwanted pregnancies and avoid sexually transmitted infections. They often respond to the needs of the region in which they are implemented. For example, in Bangladesh, local service providers are thoroughly trained on contraceptive methods, counseling and infection prevention. In Ecuador, family planning programs provide access to clinics in which local languages were spoken to reduce high fertility and mortality among indigenous communities. In Kazakhstan, with the increase in abortions following the breakup of the Soviet Union, family planning efforts tend to focus on providing information about contraception through radio, television and newspapers. While these programs vary with the context in which they are provided, the broad aim is to provide targeted reproductive health services and information to women and families.

This leads us to ask whether it is enough morally to provide individuals with universal general education, such that they are provided with the formal resources to guide their reproductive and family planning decisions on their own, or whether one must go one step further to provide universal comprehensive education as well.

There is a seemingly easy answer to this question: comprehensive family planning education has a noted effect on reducing fertility as well as infant, child and maternal mortality (Phillips et al., 1982; Hale et al., 2006). But comprehensive family planning education efforts are not necessarily at the top of the educational agenda. There are many other substantive concerns that may be competing for the same funding sources as family planning programs, including household economics, technical training, training in the use of technology and so on. We are arguing that there are strong ethical requirements to implement comprehensive family planning education.

\section{Where's the controversy?}

Much of the early debate over family planning centered on the question of what demographic objectives to pursue and what moral constraints to place on those pursuits. At the Cairo International Conference on Population and Development in 1994, the conversation shifted from a discussion focusing on demographic goals and turned instead to a discussion about empowering women through education and economic freedom. This marked a watershed moment in the trajectory of such programs. While this is an important aim, it is beset with at least one possible grievous misinterpretation: that comprehensive family planning education is unnecessary for the achievement of empowered citizenry.
For instance, criticisms of family planning programs tend to include concerns over their effects on economic development, whether there is a demand for fertility control, and program effectiveness (Seltzer, 2002). These criticisms can be readily rebutted by demographic research that shows how a reduction in fertility is associated with high economic benefits, surveys that show that women generally have an unmet need for contraception, and evidence that family planning programs work in giving families the ability to regulate their fertility. A more focused critique has been on whether the programs are cost effective compared to other alternatives, in particular, primary schooling (Summers, 1992; Gertler and Molyneaux, 1994). One report by the then Chief Economist of the World Bank argued that the provision of one year of general education for women alone is more cost effective in averting births than the cost of averting births through family planning programs, disregarding other economic and social benefits of educating women. The implication is clearly that in a world of limited resources, general education should be prioritized over comprehensive family planning education - a point with which we agree. Coupled with political objections to comprehensive family planning education as seen with Reagan's global gag rule and Philippine President Arroyo's disapproval of modern contraception, however, there may be reason to believe that one can simply stop at general education. ${ }^{2}$ This claim that comprehensive family planning education is unnecessary stems in part from the evidence that shows female general education and women's empowerment offer more 'bang-for-your-buck' than comprehensive family planning education. That is, comprehensive family planning education only offers short-term benefits with regard to reducing fertility and mortality, whereas universal education provides opportunities for women and communities to develop and prosper economically and socially. Gertler and Molyneaux (1994) estimated that in Indonesia, 87 percent of the increase in contraceptive use was due to increases in income and education accounting for 65 percent of the fertility decline, compared to family planning inputs that are responsible for merely $4-8$ percent of the fertility decline.

On average, more educated women have fewer children (due to delays in marriage, staying in school longer and lowered desire for children) and are more likely to have healthier children (in part due to longer spacing between births and also due to better health behaviors and prenatal care) (Phillips et al., 1982; Chen et al., 1983; Bongaarts, 1987; Cleland and Van Ginneken, 1988; Hale et al., 2006; DaVanzo et al., 2008). The effect of universal education on reducing fertility and 
improving infant and child health is much bigger than any efforts made for family planning. Thus, numerous analysts suggest that investment in education is the most cost-effective way to reduce fertility and improve the well-being of children throughout the developing world (Summers, 1992; Gertler and Molyneaux, 1994; Angeles et al., 2005).

Many delegates at the Cairo conference argued that the universal education of all children will lead to reduction in fertility and infant and child mortality. And thus, this will serve to improve the demographic challenges of the developing world ahead. Education leads to more advanced planning on the part of families and thus corresponds to both economic and health care advantages. Cleland estimates that each one-year increment in mother's education corresponds with a 7-9 percent decline in child mortality, in large part due to the economic advantages that accompany maternal education (e.g., higher income, clean water, better housing, etc.) (Cleland and Van Ginneken, 1988).

Thus, the controversy emerges. With all of the empirical evidence in support of the cost effectiveness advantage of universal general education over comprehensive family planning education, is comprehensive family planning education really necessary?

\section{Autonomy}

In what follows, we offer our argument by way of autonomy. We begin by fleshing out a conception of autonomy as 'control over one's life and one's life projects', where this is distinct from the mere capacity to choose. We then explain the difficulty that such a conceptual picture of autonomy poses with regard to the empirical measurement or identification. This discussion sets the stage for us to explain the role of autonomy and rights in the establishment of public policy. We then conclude that comprehensive family planning education programs are necessary because they are essential to facilitating autonomy, which lies at the heart of one core justification for universal general education policy.

\section{Autonomy as Self-legislation}

One way to understand the objective of universal education is to offer all individuals control of their lives, where the end result of their schooling is an autonomous life: a life that is self-directed and not steered by outside forces (Gutman, 1987). The old adage that giving a man a fish will only feed him for a day, whereas teaching him to fish will feed him for a lifetime, testifies to the prevalence of this commonplace view. Universal education begets autonomy, it is believed, and so it should suffice to handle most fertility issues as well. Yet this raises a complication: definitions of autonomy vary, and accusations abound that many such conceptions are woefully deficient.

The autonomy literature dominant in the public health field reveals a range of definitions of autonomy, some of which are notably problematic: one early study characterizes autonomy in technical, social and psychological terms, as an ability or capacity to use information and knowledge to make important decisions (Dyson and Moore, 1983). Subsequent work relies on similar characterizations of autonomy (Malhotra and Boender, 2002; Mullany et al., 2005). We consider these studies to rely on a relatively narrow and 'thin' conception of autonomy, and claim that this thin conception is a common view in the public health and bioethics literature. A different study has attempted to isolate five interdependent aspects of autonomy tied to education: autonomy of knowledge, decision-making autonomy, physical autonomy, emotional autonomy, and economic and social autonomy (Jejeebhoy, 2000). Jejeebhoy is not alone in identifying these multiple aspects of autonomy. Many other scientists have also sought to isolate more robust measures of autonomy, sometimes specifically with an eye toward fertility issues (Kishore, 2000; Fikree et al., 2001; Agarwal and Lynch, 2006; Ghuman et al., 2006). Yet further studies question altogether the appropriateness of women's autonomy as a way of understanding influences on women's reproductive health (Mumtaz and Salway, 2009).

The range of views on autonomy is reflected in the philosophical literature as well and tends to be considerably more conceptual, crossing over into questions regarding responsibility, freedom, paternalism and education (for a full overview see, Mackinzie and Stoljar, 2000; Christman, 2003). This discussion offers some insight into the issue regarding universal versus comprehensive education (Burtt, 2003). A sizable number of philosophers, for instance, subscribe primarily to a 'procedural' view of autonomy, derived in many cases from the philosopher Immanuel Kant (Dworkin, 1988; Christman, 1989, 2005; Benson, 1994; Friedman, 1997; Stoljar, 2000; Christman and Anderson, 2005; our list is not exhaustive). According to Kant, the free agent is the agent whose will is in control of the maxims by which he operates. Thus, the free agent is self-legislating, or autonomous (auto: self; +nomos; law giving), and not simply free to make choices. In diluted form, this intuition permeates many conceptions of free agency, including those thin conceptions expressed above. ${ }^{3}$ The Kantian view of the autonomous agent as a self-legislator 
is therefore intermingled with other conflicting conceptions of autonomy-most prevalently, as freedom from constraint - in contemporary education theory. Those who believe that education gives individuals the resources to begin the arduous project of gaining control over their lives, of becoming autonomous, subscribe to variations on this thin picture of 'formal' or 'procedural' autonomy (Gutman, 1987; Schwab, 2006). Yet if this Kantian definition of autonomy is taken too rigidly, it dissolves into an empty formalism, in which the autonomous agent is guided by little more than the efficacy with which she is able to set principles.

The 'empty formalism objection' has been lodged in several contexts, not all of which are appropriate to discuss here (Meyers, 1987; Benson, 1994, 2005; Friedman, 1997; O’Neill, 1997; Stoljar, 2000; Schwab, 2006). Speaking loosely, the charge is that a view of autonomy that strictly privileges the legislative aspects of agencyprocedural autonomy-is ineffectual since it can draw on no specific values or principles by which to guide action. One suggested remedy to this empty formalism is to 'thicken' the picture by acknowledging that substantive concerns are part and parcel of agency.

In the case of reproductive and family planning practices, one can understand the implications of this objection by interrogating intuitions about responsibility. If an agent is not provided with the substantive resources, accompanied by the formal means, necessary to come to an informed and intelligent decision about how to prevent or instigate reproduction or how to bring about a healthy pregnancy, we believe many would argue that it is wrong to claim that the agent must be or can be held fully responsible for her actions. If, for instance, a universally but not comprehensively educated young woman of disadvantaged background-raised in a culture with religious taboos on discussions of sexbecomes pregnant at an early age and in an unsafe manner, it is hard to find fault with her for not having known the consequences that her actions might bring. Though she may be reasonably well educated and therefore autonomous in the sense that she is free to lead her own life, this sort of autonomy cannot alone sufficiently account for responsibility. There must be something more substantive. She must also have been taught about sex and fertility, about pregnancy and about her options, in order to say that she was culpable, as an autonomous agent, for having brought about her predicament. This is the difference between procedural and substantive autonomy.

In turn, autonomy is tied tightly to human rights, so it matters significantly what picture of autonomy (procedural or the substantive) one adopts (Mackinzie and Stoljar, 2000). The question of the right of women to comprehensive education enters at the juncture between justice and autonomy since the Tehran conference and all subsequent conferences have reaffirmed the principle that 'parents have a basic human right to determine freely and responsibly the number and spacing of their children'. If authority over one's reproduction is indeed a right-and we believe it isthen there is little sense in suggesting that the right can be fulfilled by simple access to universal and general education, compelling though this view may be. ${ }^{4}$ This position was reaffirmed, and indeed strengthened, at the 1974 Bucharest World Population Conference: 'All couples and individuals have the basic right to decide freely and responsibly the number and spacing of their children and to have information and means to do so; the responsibility of couples and individuals in the exercise of this right takes into account the needs of their living and future children, and their responsibilities towards the community' (quoted in UNFPA, State of World Population, 1997, italics our own). It continued to be strengthened in the 1994 ICPD Programme of Action, which insists that the 'aim of family-planning programmes must be to enable couples and individuals to decide freely and responsibly the number and spacing of their children and to have the information and means to do so and to ensure informed choices and make available a full range of safe and effective methods' (quoted in UNFPA, State of World Population, 1997, italics our own). If universal education is to be truly universal, it must be attentive to the socio-historical circumstances of both sexes; it must apply in such a way that the substance of the principles can realistically be upheld.

We recognize that much of the research on fertility and childbearing bears out the conclusion that universal general education programs facilitate forward-looking reproductive choices. But we are also critical of the idea that once general education has been adopted as universal, comprehensive educational practices are unnecessary. General education is dependent upon certain baseline requirements that give rise to opportunities for general education to take root. That procedural autonomy can dissolve into emptiness might not be a problem or could be understood as simply a tradeoff. What makes it a problem is that autonomy is inextricably tied up in questions of rights. Because some women are likely to suffer obstructed opportunities for autonomy and some don't receive universal education at all, we maintain that the state is required morally to administer widespread comprehensive education programs. Anything else would be unfair.

Those who make family planning decisions strictly by appeal to available choices, but without guidance from substantive norms (norms including, but not limited to, 
standards of care, family size expectations, social and cultural opportunities and maternal health options), are effectively not acting autonomously but instead heteronomously. Take, for example, the hypothetical case of a woman who defaults into a position in which she feels compelled to make a family planning decision. Suppose that, given her circumstances, she chooses to avoid parenthood (via termination, say) because it will interfere with her job or life or because she cannot afford a child. From her perspective, her options are closed. This is a woman who is, arguably, in a similar position to a woman who becomes pregnant and cannot escape the pregnancy because the resources (for a termination, say) or the facts (about termination) are not made available to her. From her perspective as well, her options are closed. If, on the other hand, we take the case of a woman who has legislative authority over her actions, as well as executive foreknowledge to inform her in her decision making, such that resources and opportunities are not closed to her (thanks to comprehensive family planning programs), we can see more clearly that this latter woman is truly at liberty to legislate for herself-and is autonomous.

\section{Empirical Evidence of Autonomy from Family Planning Programs}

Autonomy is notoriously slippery, sometimes characterized as freedom from constraint and sometimes characterized as self-governance or self-legislation. Unfortunately, empirical studies can never tell the whole story on this distinction since self-legislation is not open to observation. The only observable trace of autonomy is, arguably, as freedom of choice, though even this is up for expansive philosophical dispute. In this case, it is conceivable, though untestable, that universal education policies more successfully foster the freedom of choice and not so much self-legislation in the Kantian sense. What is likely to be the case, we hypothesize, is that because of the problem of empty formalism, if universal education is taught too generally, it can create the illusion that an individual has become autonomous (in the Kantian sense) when it is only the case that they have been given the ability and resources to make choices that have been determined or laid out for them by others (e.g., heteronomously). They may, for instance, choose a set of options for their lives that are subject to constraints imposed by external state actors, without knowledge, say, of options for contraception and/or pregnancy termination. If, on the other hand, and as the evidence suggests (but does not definitively demonstrate), comprehensive education programs, coupled with programs of universal general education, provide individuals with the resources to make informed decisions for themselves, we can avoid the problem of empty formalism.

Indeed, empirical studies demonstrate that family planning programs reduce fertility and infant and child mortality above and beyond traditional development indicators such as women's education. For example, one study estimates that the difference between scenarios that have family planning and those that do not is around 4.6 billion people by the year 2100 (Bongaarts et al., 1990). In addition, the experimental MCH/FP program offered to a randomly assigned portion of the demographic surveillance system in Matlab, Bangladesh, show strong evidence that increased access to contraception and maternal and child health services directly reduces fertility (Phillips et al., 1982) and child mortality (Hale et al., 2006). Further, previous literature may have overestimated the effect of education on fertility and health outcomes by failing to account for endogeneity issues (Angeles et al., 2005).

But just because there is generally positive movement indicating that comprehensive family planning education improves the life options of individuals, this does not necessarily imply that one must follow through with a program of family planning. Something more than simple outcomes that reflect apparent choices must be in place. This can be supported empirically. Research shows that comprehensive education programs facilitate, rather than simply augment, universal education programs. Angeles and colleagues demonstrate that family planning programs early in a woman's life increase her educational attainment at the general level (Angeles et al., 2005). In addition, Angeles cites evidence that family planning programs increase general education of children of women who have benefited from family planning programs. Thus, comprehensive family planning and universal education are mutually supportive.

\section{Family Planning as the Right Way to Offer Autonomy to Women}

The commonplace view understands autonomy in terms of the capacity that one has to maintain control of one's life. A particularly important dimension along which one can be said to be autonomous is in the area of family planning - directly in the case of many women and indirectly in the case of many men. The argument for universal education implies that as long as the opportunities for education and family planning are 
available, individuals need only be provided with the resources to pursue such avenues should they so choose. But it is also the case that there must be a baseline level of met needs for universal education to beget autonomy.

In other words, if we understand the relationship between autonomy and education as tied strictly to the formal view such that the relationship is unidirectionaluniversal general education begets autonomy - then we underdetermine the extent to which one's autonomy is in part determined by the decisions of one's progenitors. If, on the other hand, we recognize that general education makes autonomy possible only under certain conditions, then we can recognize that some substantive requirements, such as family planning education, must be met in order for general education to take root.

Putting this all another way, suppose the following: suppose that 80 percent of the population can be said to receive family planning benefits of reduced unwanted children and increased family health from the implementation of universal general education. Suppose that these numbers break down such that 60 percent of these (3/4 of the 80 percent) are raised to the level of genuinely resourceful and capable agents but that 20 percent ( $1 / 4$ of the 80 percent) are passive bystanders about their reduced family size and improved health. (We'll call these the 'Lucky 20\%'.) In other words, in a world with universal education, this Lucky $20 \%$ may end up differently than they would in a world in which they have not gotten universal education, in terms of having both of a smaller (potentially more desired) family size with healthier children. This may be due to shifts in cultural norms and behaviors rather than true control over their family planning decisions. Maybe they spend more time in the library, or they take interest in other things. Those in this Lucky $20 \%$, we can suppose, are fortunate in that they are the beneficiaries of positive externalities from universal education, but they are passed over as truly in control of their family lives because they are not themselves making informed family planning choices. They are the beneficiaries of circumstances arising from an alternative social arrangement.

Now suppose a second case. In this case, comprehensive family planning programs educate the entire population, thus reducing the percentage of unwanted pregnancies and reducing mortality and morbidity rates among women and children. In this case though, while it appears that the increase in total coverage of the population only slightly, say from 80 percent to 85 percent, what may actually be happening is that that Lucky $20 \%$ are also now better able to make informed decisions about their own reproductive health and family size. They are better informed, more critical and more attuned to their needs, their partner's needs and their future. So, on our hypothetical example, it may appear that implementation of comprehensive education programs only contributes to a 5 percent benefit over universal education, but what is actually happening is that 25 percent of the population (the Lucky $20 \%$ as well as the additional 5 percent) is brought to the point of substantive autonomy.

The claim, then, is that we face a falsely concrete dichotomy if we carve up educational programs along simple cost-benefit lines. Universal education is too formal; it doesn't succeed in giving individuals the resources that they need to become autonomous, which is a necessary but not a sufficient stepping stone to making wise family planning decisions. Universal education must contain a substantive component, and the discussion should not simply be about which of the two options provides the greatest benefit or whether comprehensive education provides a strong enough benefit to warrant its implementation over and above a program of universal education.

To put this in yet a different way: if we think universal general education programs can provide only the rudiments of autonomy such that agents can then adequately choose for themselves, we are sorely mistaken. We cannot, in other words, just teach a man to fish if we do not also, at the same time, teach him to eat fish and give him some fish to eat as well. The prospective fisherman has little reason to care about fishing if he is not also taught to appreciate fish. The question, in the end, is about the most efficacious method for training someone to fish. To believe that this training could somehow leave out critical substantive details is to lean too heavily into the wafer-thin autonomy that guides much proceduralist moral and political theory. You give people an opportunity to succeed and become autonomous by giving them comprehensive training in a general education.

So we can see that the issue of family planning is just as much tied to autonomy as some of the other issues that otherwise burden the educational system. If an educational program seeks to cultivate autonomy by providing a universal and generalized curriculum, it must also offer up the content-rich resources such that its students can find the liberation to think and act for themselves. The only conditions under which one can be said to ensure liberation from the external fetters of heteronomy is by offering comprehensive family planning education geared to address such matters as pregnancy, childbirth, childrearing and nutrition for children and families. 


\section{Conclusion}

There are many ways to understand the arguments in favor of comprehensive education programs, such as picking up the slack of those who have fallen through the universal education cracks, offering the basic information necessary for individuals to make critical family planning choices or providing a net benefit over universal education programs. By contrast, comprehensive family planning education programs can be criticized on grounds that they are too paternalistic, too expensive or unnecessary. We argue against the latter criticism of comprehensive education programs here: reasoning that they are necessary because they are an essential component to truly facilitating the autonomy at the heart of universal general education policy.

Universal education depends on the establishment of procedural autonomy in citizens. As many critics of Kant and the neo-Kantians have suggested, there is a danger in understanding autonomy too formally: procedural autonomy can dissolve into empty formalism. In other words, with regard to particular requirements and duties, it can be too empty to provide a non-arbitrary guide to action. It must instead be propped up by substantive guidance. In this case, the substantive guidance required is that which aids in the establishment and promotion of autonomy. This need not include guidance on how to live one's life, or in what is good or in what the normative expectations of a given community are. This does need, however, to include guidance in the rudiments of what it takes to maintain the practical preconditions for procedural autonomy: conditions like how to remain nourished, how to avoid disease and death, how to successfully pursue certain ends and how to avoid constraints.

Family life is rudimentary to our degree of autonomy in at least three ways: it is a health concern, it is a concern over possibilities and life choices (children function as dependents and constrain our possibility) and finally, when families are ill informed about family planning opportunities, they may have either unwanted or mistimed pregnancies, which impact significantly the preconditions that give rise to autonomy. If we aim to support autonomy, then we must also support a policy that lays the groundwork for it to take root, which includes both universal and comprehensive education.

\section{Notes}

1. This right is reflective of the view that individual autonomy is an end worth promoting and, indeed, that there is a moral obligation to promote autonomy. The so-called 'right' to education, then, stems from a commitment to facilitate the autonomy of others.

2. Some readers may take umbrage with our claim that such arguments about the cost effectiveness of universal education imply that comprehensive education is unnecessary. Yet here we use the term 'unnecessary' on moral grounds specifically, not practical or logical grounds. In other words, we are suggesting that when one implies, intimates or suggests outright that universal education is more cost effective and that resources would be better spent elsewhere, one is suggesting as well that comprehensive family planning programs are morally unnecessary. This is akin to saying not only that resources would be better spent elsewhere but also that our responsibilities will be fulfilled if resources are better spent elsewhere.

3. The late Joel Feinberg clarifies at least four confusing uses of the term: 'It can refer either to the capacity to govern oneself...or the actual condition or self-government...or to an ideal of character derived from that conception; or...to the sovereign authority to govern oneself (1986: 28).

4. The language of rights can be somewhat arcane, so we prefer instead to frame this discussion in terms of autonomy-arguably an equally mysterious term. We raise the rights position only because the debate has historically been framed around rights. It is our view that women must at minimum be equipped with the resources to entertain the full range of fertility opportunities available to them. Far from an overly demanding requirement that all available resources be spent to ensure that women have access to fertility means and methods, this requirement should instead be understood as positive, but bearing in mind that positive requirements such as these can only ever be imperfectly fulfilled. This has parallels with other positive rights: a right to education requires that citizens be enabled with the resources to steer their own lives so that they then have a more robust range of opportunities available to them. This no more requires that all students be given the resources to pursue these opportunities than does the moral requirement that women be educated about fertility and women's health require that women be outfitted with access to sonograms or genetic testing. What it instead requires is that they be provided with resources that would enable them to pursue, so far as is reasonably plausible, relevant opportunities. 


\section{References}

Agarwal, R. and Lynch, S. (2006). Refining the Measurement of Women's Autonomy: an International Application of a Multi-dimensional Construct. Social Forces, 84, 2077-2098.

Angeles, G., Guilkey, D. K. and Mroz, T. A. (2005). The Effects of Education and Family Planning Programs on Fertility in Indonesia. Economic Development and Cultural Change, 54, 165-201.

Benson, P. (1994). Free Agency and Self-worth. Journal of Philosophy, 650-668.

Benson, P. (2005). Feminist Intuitions and the Normative Substance of Autonomy. In Taylor, J. S. (ed.), Personal Autonomy. New York: Cambridge University Press.

Bernstein, S. (2005). Reproductive Health and the UN Millennium Development Goals. Studies in Family Planning, 36, 127-132.

Bongaarts, J. (1987). Does Family-Planning Reduce Infant-Mortality Rates? Population and Development Review, 13, 323-334.

Bongaarts, J., Mauldin, W. P. and Phillips, J. F. (1990). The Demographic Impact of Family Planning Programs. Studies in Family Planning, 21, 299-310.

Burtt, S. (2003). Comprehensive Educations and the Liberal Understanding of Autonomy. In Feinberg, Walter and McDonough, K. (eds.), Education and Citizenship in Liberal-Democratic Societies. Oxford: Oxford University Press.

Chen, L. C., Rahman, M., Dsouza, S., Chakraborty, J., Sardar, A. M. and Yunus, M. (1983). Mortality Impact of an MCH-FP Program in Matlab, Bangladesh. Studies in Family Planning, 14, 199-209.

Christman, J. (ed.) (1989). The Inner Citadel: Essays in Individual Autonomy. New York: Oxford University Press.

Christman, J. (2003). Autonomy in Moral and Political Philosophy. In Zalta, E. N. (ed.), The Stanford Encyclopedia of Philosophy. http://plato.stanford. edu/entries/autonomy-moral/.

Christman, J. (2005). Procedural Autonomy and Liberal Legitimacy. In Taylor, J. S. (ed.), Personal Autonomy. New York: Cambridge University Press.

Christman, J. and Anderson, J. (eds.) (2005). Autonomy and the Challenges to Liberalism: New Essays. New York: Cambridge University Press.

Cleland, J. G. and Van Ginneken, J. K. (1988). Maternal Education and Child Survival in Developing Countries: the Search for Pathways of Influence. Social Science and Medicine, 27, 1357-1368.

DaVanzo, J., Hale, L., Razzaque, A. and Rahman, M. (2008). The Effects of Pregnancy Spacing on Infant and Child Mortality in Matlab, Bangladesh: How They Vary by the Type of Pregnancy Outcome that Began the Interval. Population Studies (Cambridge), 62, 131-154.

Dworkin, G. (1988). The Theory and Practice of Autonomy, New York: Cambridge University Press.

Dyson, T. and Moore, M. (1983). On Kinship Structure, Female Autonomy, and Demographic Behavior in India. Population and Development Review, 9, 35-60.

Feinberg, J. (1986). Harm to Self, New York: Oxford University Press.

Fikree, F., Khan, A., Kadir, M., Sajan, F. and Rahber, M. (2001). What Influences Contraceptive Use among Young Women in Urban Squatter Settlements of Karachi, Pakistan. International Family Planning Perspectives, 27, 130-136.

Finkle, J. L. and Crane, B. B. (1975). Politics of Bucharest-Population, Development, and New International Economic Order. Population and Development Review, 1, 87-114.

Finkle, J. L. and Crane, B. B. (1985). Ideology and Politics at Mexico City-the United States at the 1984 International Conference on Population. Population and Development Review, 11, 1-28.

Friedman, M. (1997). Autonomy and Social Relationships: Rethinking the Feminist Critique. In Meyers, D. T. (ed.), Feminists Rethink the Self. Boulder: Westview.

Gertler, P. J. and Molyneaux, J. W. (1994). How Economic Development and Family Planning Programs Combined to Reduce Indonesian Fertility. Demography, 31, 33-63.

Ghuman, S., Lee, H. and Smith, H. (2006). Measurement of Women's Autonomy according to Women and Their Husbands: Results from Five Asian Countries. Social Science Research, 35, 1-28.

Gutman, A. (1987). Democratic Education, Princeton: Princeton University Press.

Hale, L., DaVanzo, J., Razzaque, A. and Rahman, M. (2006). Why Are Infant and Child Mortality Rates Lower in the MCH-FP Area of Matlab, Bangladesh? Studies in Family Planning, 37, 281-292.

Jejeebhoy, S. (2000). Women's Autonomy, in RURAL INDIA: Its Dimensions, Determinants, and the Influence of Context. In Presser, H. and Sen, G. (eds.), Women's Empowerment and Demographic Processes: Moving beyond Cairo. New York: Oxford University Press.

Kishore, S. (2000). Women's Contraceptive Use in Egypt: What Do Direct Measures of Empowerment Tell Us? Paper Presented at the Annual Meeting of the Population Association of America, 24-25 March 2000, Los Angeles. 
Levinson, M. (1999). The Demands of Liberal Education, Oxford: Oxford University Press.

Malhotra, S. and Boender, C. (2002). Measuring Women's Empowerment as a Variable in International Development, Washington: The World Bank, Gender and Development Group and Social Development Group.

Mackinzie, C. and Stoljar, N. (2000). Introduction. Relational Autonomy: Feminist Perspectives on Autonomy, Agency, and the Social Self, New York: Oxford University Press.

Mcintosh, C. A. and Finkle, J. L. (1995). The Cairo Conference on Population and Development-a New Paradigm. Population and Development Review, 21, 223-260.

O'Neill, O. (1997). Towards Justice and Virtue: a Constructive Account of practical Reasoning, Cambridge: Cambridge University Press.

Meyers, D.T. (1987). The Socialized Individual and Individual Autonomy. Women and Moral Theory, Savage: Rowman and Littlefield. 239-54.

Mullany, B. C., Hindin, M. J. and Becker, S. (2005). Can Women's Autonomy Impede Male Involvement in Pregnancy Health in Katmandu, Nepal? Social Science and Medicine, 61, 1993-2006.

Mumtaz, Z. and Salway, S. (2009). Understanding Gendered Influences on Women's Reproductive Health in Pakistan: Moving Beyond the Auton- omy Paradigm. Social Science and Medicine, 68, 1349-1356.

Phillips, J. F., Stinson, W. S., Bhatia, S., Rahman, M. and Chakraborty, J. (1982). The Demographic Impact of the Family Planning-Health-Services Project in Matlab, Bangladesh. Studies in Family Planning, 13, 131-140.

Rawls, J. (1993). Political Liberalism, Columbia University Press: New York. 199.

Schwab, A. P. (2006). Formal and Effective Autonomy in Health Care. Journal of Medical Ethics, 575-579.

Seltzer, J. (2002). The Origins and Evolution of Family Planning Programs in Developing Countries, MR1276, Santa Monica: RAND.

Son, J. (2005). Inter-Press News Service, 20 November. Church, a Goliath against Reproductive Health, http:// www.religiousconsultation.org/News_Tracker/ Church_a_goliath_against_reproductive_health.htm.

Stoljar, N. (2000). Autonomy and the Feminist Intuition. In Mackinzie, C. (ed.), Relational Autonomy: Feminist Perspectives on Autonomy, Agency, and the Social Self. New York: Oxford University Press.

Summers, L. H. (1992). Investing in all the People, World Bank Policy Research Working Paper 905.

UNFPA. (1997). State of World Population, http://www. unfpa.org/swp/1997/swpmain.htm.

Weber, E. T. (2008). Dewey and Rawls on Education. Human Studies, 31, 361-382. 